\title{
Effect of soiling in CPV systems
}

\author{
M. Vivar \\ R. Herrero \\ I. Antón \\ F. Martínez-Moreno \\ R. Moretón \\ G. Sala \\ A.W. Blakers J. Smeltink
}

\begin{abstract}
The effect of soiling in flat PV modules has been already studied, causing a reduction of the electrical output of $4 \%$ on average. For CPV's, as far as soiling produces light scattering at the optical collector surface, the scattered rays should be definitively lost because they cannot be focused onto the receivers again. While the theoretical study becomes difficult because soiling is variable at different sites, it becomes easier to begin the monitoring of the real field performance of concentrators and then raise the following question: how much does the soiling affect to PV concentrators in comparison with flat panels?' The answers allow to predict the PV concentrator electrical performance and to establish a pattern of cleaning frequency. Some experiments have been conducted at the IES-UPM and CSES-ANU sites, consisting in linear reflective concentration systems, a point focus refractive concentrator and a flat module. All the systems have been measured when soiled and then after cleaning, achieving different increases of $I_{\mathrm{SC}}$. In general, results show that CPV systems are more sensitive to soiling than flat panels, accumulating losses in $I_{\mathrm{SC}}$ of about $14 \%$ on average in three different tests conducted at IESUPM and CSES-ANU test sites in Madrid (Spain) and Canberra (Australia). Some concentrators can reach losses up to 26\% when the system is soiled for 4 months of exposure.
\end{abstract}

Keywords: Concentration; Soiling; Losses; Field performance

\section{Introduction}

Why is the effect of soiling on a solar collector an issue of interest?

In general, dirt from ambient air including dust, rain, pollution and other particles on photovoltaic modules (Fig. 1) affects their electrical performance, reducing the energy output. The main affected quantity is the short circuit current, $I_{\mathrm{SC}}$, which can be approximately $3 \%$ lower when the panels are soiled. In some specific orientations this parameter can reach a loss of $8 \%$, when the panel is almost horizontal, $0^{\circ}$ (Becker et al., 1996; Haeberlin and Graf, 1998). Current loss in concentrator modules is generally more severe than in non-concentrator modules, since forward scattering of light from dust particles has a greater affect.

Several studies have been performed in order to quantify soiling loss in photovoltaic (PV) and thermal solar concentrator systems (Becker et al., 1996; Haeberlin and Graf, 1998; Hottel and Woertz, 1942; Biryukov et al., 1999; Garg, 1974; Deffenbaugh et al., 1986; Hammond et al., 1997; Hegazy, 2001; Elminir et al., 2006; Stone et al., 2004). Numerous factors are involved in soiling, including location, climate and collector orientation. In addition the cost of keeping a system clean should be traded off against loss of performance from system soiling.

Concentrator PV (CPV) systems use an optical system to collect the sunlight and focus it onto the cells. As a result CPV systems can only use the direct beam component of 


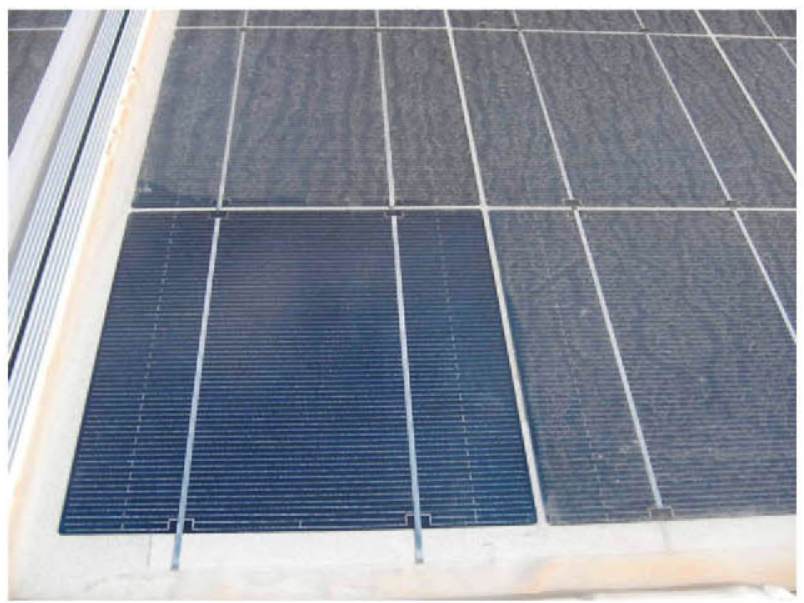

Fig. 1. Partially cleaned soiled module, where we can observe the difference between a clean cell and the rest of the module.

sunlight. When soiling occurs on the collector surfaces, a significant proportion of the light is scattered and lost because the optical system is not able to focus it onto the solar cell. On the other hand, conventional non-concentrating panels are able to use both direct and indirect light that is scattered from dust particles on the glass encapsulation, provided that this light is forward-scattered onto the solar cells. CPV system efficiency is much more sensitive to soiling than that of flat panel PV systems.

The theoretical study of soiling is difficult because soiling is very dependent upon location, tilt and other variables. Perhaps monitoring of the real field performance of concentrators may be a better approach and provide answers to the following questions:

- 'How much does the soiling affect to PV concentrators in comparison with flat panels?' and

- 'Is the effect of the soiling related to the concentration level?'

Answers to these questions will provide the capability to predict the electrical performance of the PV concentrator over time and a way to establish an economical cleaning regime.

The main objective of this paper is the study of the effect of soiling in CPV systems and its comparison with flat plate PV modules while subjected to diverse regimes of comparable soiling.

Previous work on soiling of solar conversion systems is reviewed, including both photovoltaic and solar thermal concentrator and non-concentrator systems.

The results of experiments carried out at IES (Instituto de Energía Solar) are presented, including testing on light dispersion in the different optical systems (glasses, lenses and mirrors) when soiled, and the effect on their transmittance and reflectance. Finally, results are presented from the testing of diverse concentrators at the IES and the Australian National University (ANU) with different concentration levels, and conclusions are drawn.

\section{Previous research on the effect of soiling in solar thermal systems and flat PV modules}

The effect of dirt in solar systems is not a new issue. When the first solar concentration thermal systems were installed in the early forties, it became immediately a matter of interest when it was identified as one of the factors that could substantially reduce the energy output of a system. From the 1970s, when PV non-concentrator technology became widely available, the effect of soiling was the subject of several studies. However, literature about soiling is relatively scarce. Some work relates to PV, while the majority relates to solar hot water panels and solar thermal concentrators.

\subsection{Solar thermal systems}

A summary of previous work on soiling in solar thermal systems has been conducted. In general, losses of up to $5 \%$ of power output were observed when using flat solar collectors after 3 months without cleaning. For the specific case of a parabolic trough concentrator located in a harsh environment (desert), losses of about $12 \%$ were observed after 20 days without washing.

The first work on the effect of dust on solar collectors was from Hottel (Hottel and Woertz, 1942) in 1942, when he and his group performed different testing of solar collectors oriented at an angle of $30^{\circ}$ to the horizontal. These panels stood three months without washing in an industrial area that included a power plant and a four-track railroad $90 \mathrm{~m}$ far away (Boston, USA). The effect of dirt was established as a reduction in the energy output of 5\%.

Biryukov et al. (1999) conducted different experiments to study the effect of dust accumulation in a solar collector. The first experiment tried to correlate the loss of electrical efficiency and the dust coverage and its distribution on the collector area by using a CCD camera. First, they measured the sizes of the particles that were on the collector surface as well as the coverage fraction of the collector, i.e. how much area of the collector was covered by dust. From this coverage, they estimated the reduction in optical efficiency. Then, they measured the electrical performance of the solar photovoltaic panel to evaluate the effect of soiling in the electrical output. The main effect of soiling in the PV panel was a loss in short circuit current. When comparing this figure with the initial estimation based in the dust coverage fraction, this loss was considerably lower than the proportion of the panel obscured by dust $(0.5 \%)$, leading to the conclusion that a substantial proportion of scattered light was scattered forward onto the solar cells.

In the second experiment, Biryukov et al., also did an experiment using mirrors, trying to identify differences in reflectance when the systems were tracked or not. In this case, they installed one mirror in an one-axis tracker and another in a static structure tilted at $0^{\circ}$. The result was that the static horizontal mirror accumulated four times more 
dust than the tracking mirror, which is an interesting result when thinking of CPV systems.

Other work was based not in the complete solar collector but in the individual components. For example, Garg (1974) studied the effect of dirt on the transmittance of different samples of glass with diverse orientation angles relative to the horizontal $\left(0^{\circ}-90^{\circ}\right)$. These samples were exposed during two months without cleaning, and periodically tested during this period. Results showed an $8 \%$ of losses in transmittance after 30 days for glass oriented at $45^{\circ}$. Plastic film was also tested by Garg, with poor results due to the fact that the dust adheres better to a plastic because of its electrostatic properties.

Deffenbaugh in 1986 (Deffenbaugh et al., 1986) studied the effect of dust in a solar concentrator system, in this case a parabolic trough concentrator. He compared the field performance of three collectors located in San Antonio (Texas, USA), El Paso (Texas, USA) and Lovington (New Mexico, USA) when affected by dust. Maximum typical degradations on energy output observed were $1.3 \%$ per day for San Antonio, $0.7 \%$ for El Paso and 1.3\% for Lovington. Deffenbaugh also found that collectors located in desert environments had higher risk of degradation due to the low rain fall and the high level of atmospheric dust.

Deffenbaugh et al. (1986) studied the frequency with which concentrator solar collectors should be washed. It was determined that in order to maintain an output of $95 \%$ of the clean condition, solar collectors should be washed daily. However, cleaning has a cost which includes labour, consumables and plant outage. On the other hand, reduced cleaning frequency incurs the loss of collected energy. Deffenbaugh suggested finding an optimum pattern of washing for each location depending on local conditions. Optimum wash frequencies for the typical degradation rate were established as 45 days (El Paso) and 20 days (Lovington). With these frequencies, the total losses for the entire year compared with ideal (perfectly clean) annual performance were between $5 \%$ and $12 \%$.

\subsection{Flat PV panels}

Soiling, including dust and pollution, affects the electrical performance of PV modules. Shading of the cells due to dirt can decrease the output of the PV system by between $2 \%$ and $10 \%$. Relevant work has been analysed.

Becker et al. (1996) in 1996 undertook a study in the framework of the German 1000-Roofs-PV Programme. $2200 \mathrm{PV}$ systems were installed on the roofs of houses in Germany. This study on the field performance of the systems analysed different factors, including the influence of the surroundings and the effect of soiling on the modules. Results showed an increase of the energy output after cleaning of about a $2-6 \%$ for modules installed with $30^{\circ}$ angle. Some of the causes of the reduction in output were found to be due to pollution, including soot, briquette, coal and poorly adjusted oil burners, in addition to biological soiling which included pollen, bird droppings and the growth of moss.

Hammond et al. (1997) studied the effect of dust in PV panels installed at the Arizona Public Service Company (APS) Solar Test and Research Center (STAR). In this case the effects were measured based on the degradation of the $I_{\mathrm{SC}}$. Results on degradation showed losses of between $2 \%$ and $8 \%$. Some factors identified in this work were the effect of soiling due to bird droppings, much more serious than soiling due to dust and dirt. It was observed that rain falls exceeding $5 \mathrm{~mm}$ reduced the losses to about $5 \%$. Authors of this work also suggested that it might be cost-effective to clean modules which are in a fixed position, and that it could also be cost-effective to clean concentrator modules.

Haeberlin and Graf (1998) reported on the testing of PV modules tilted at $30^{\circ}$ and installed in a region with a mix of light industry, forest and farms. Biological pollution was noted as a source of soiling, particularly pollen in springtime. Results showed a power output degradation of $8-10 \%$. As a novelty, this group was interested in the composition of the polluting material. Analysis using dispersive micro-X-ray analysis revealed the presence of iron particles (surrounded by iron oxide) and even silicon from sand which originated from the Sahara desert. In general, it is difficult to determine the effect of the different particles and materials on soiling. But in areas with high losses due to soiling, it might be interesting know the composition of the pollutants, in order to plan an effective cleaning.

Hegazy (2001) and Elminir et al. (2006) studied how dust affected the transmittance of clear glass samples exposed to the environment. After 30 days, Hegazy showed losses of $27 \%, 17 \%$ and $3 \%$ for $0^{\circ}, 30^{\circ}$ and $90^{\circ}$ tilt, respectively. Elminir recorded losses of $27 \%, 18 \%$ and $6 \%$ for $0^{\circ}, 30^{\circ}$ and $90^{\circ}$ tilt, respectively. Both sites were located in Egypt, the first site corresponded with a region of strong pollution from agricultural fields and strong pollution from industry surrounding in the second one.

\subsection{Previous work in $C P V ' s$}

There are few previous studies of the effect of soiling on concentrator photovoltaic systems. The Amonix concentrator was the subject to one study (Stone et al., 2004). This is a concentration system that uses Fresnel lenses at a concentration ratio of $300 \mathrm{X}$ (and $400 \mathrm{X}$ in later versions). The system under test is located at the Arizona Public Service STAR facility in Tempe, Arizona (USA). The main identified factors in the energy degradation were due to pollution, the condition of the ground terrain including dust, sand, grass and pollen, the site around the immediate area and other factors such as windy and rainy periods. Results of soiling on this system show that after a high-pressure spray from ground, the string current increased about $15 \%$ after one month without washing. 


\section{Effect of soiling in CPV's}

Concentrating PV systems differ from flat PV panels in that an optical system is used to focus the direct component of solar radiation onto the solar cells. This optical system may be adversely affected by soiling because the radiation that is not within the acceptance angle of the optical system is lost. CPV systems may be more susceptible to loss related to soiling, since most scattering of light by dust, whether it is forward or not, will result in loss of that light. For this reason, Haeberlin and Graf (1998) suggested that concentrator PV modules were probably more cost-effective to clean more often than flat PV modules.

\subsection{Effect of soiling in single optical systems: lenses and mirrors}

When sunlight falls upon a soiled lens (Fig. 2), each soil particle will partially absorb the light and partially scatter it. Both effects will reduce solar power transmission, as also it does in flat panels.

However, scattering also produces deviation of the light resulting in a failure of that light to reach the solar cell. In the case of a mirror (Fig. 3), there are opportunities for scattering and absorption at both the entry and exit points of the mirror for each ray of light.

Single optical systems have been chosen for analysis by IES-UPM to determine the effect of soiling. In addition several experiments were conducted on concentrator systems that utilise either lens or mirror optics.

Soiling experiments have been carried out at IES-UPM on plain glass and glass mirrors using both artificial and natural soil. In the first experiment, the soiled surfaces were created artificially. They consisted of four types of mirrors and common flat clear glass (diamond glass type from Saint-Gobain) used in CPV systems. The process of soiling



Fig. 2. Effect of a particle of dirt in a lens.



Fig. 3. Effect of a particle of dirt in a mirror.

artificially the surfaces consisted of depositing uniformly the soiling materials onto each type of surface. The soiling materials used were limestone, cement and carbon. They were suspended in water at different concentrations, and the suspension was deposited onto the samples. Once the water evaporated, the material became affixed to the sample in a manner similar to natural soiling. After soiling the surfaces, they were examined under an optical microscope for checking the particle deposition uniformity. The accumulated dust density was determined by measuring the weight of a glass sample before and after soiling.

The losses in transmittance and reflectance were of $20 \%$ on average (Table 1). Measurements were performed using a pixel intensity calibrated CCD camera. The camera was used as a detector of the transmittance coefficient as well as a detector of the ray scattering (or angular dispersion of rays). The set-up consisted of a tungsten lamp located into a box which allowed the emission of light through a circular Lambertian window. The window diameter and the distance to the soiled glass (or mirror) samples were selected to obtain an angular point of view of the window such as the sun disk in earth $\left( \pm 0.27^{\circ}\right)$. The comparison of the window image through a clean glass and through a soiled one provided the mentioned information: the module variation and the increased angular ray distribution. The details of how the camera was focused and how the light bundles by soiling were modified will be presented shortly in another article (Herrero, 2008).

In the second experiment, glass samples (Fig. 4) were placed outdoors near the CPV systems for long term

Table 1

Effect of artificial soiling in optical surfaces. $\theta$ is the field of view of the CCD camera.

\begin{tabular}{ll}
\hline Surface & $\begin{array}{l}\text { Artificial dirt: cement losses } \\
\text { due to soiling } \theta=1^{\circ}(\%)\end{array}$ \\
\hline Aluminium second surface & 42.67 \\
Aluminium film & 27.5 \\
Aluminium sheet & 7.48 \\
Silver film & 15.34 \\
Glass & 11.79 \\
\hline
\end{tabular}




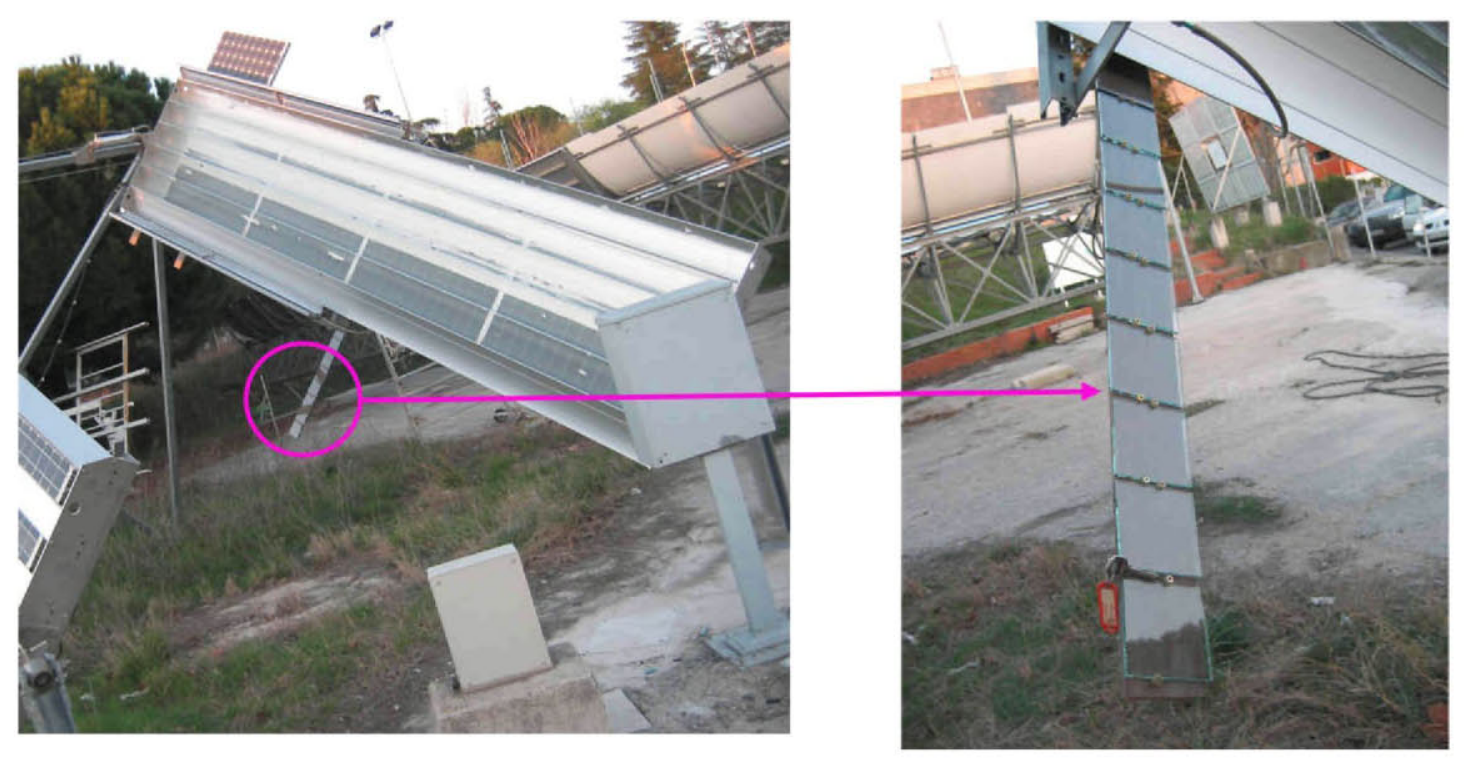

Fig. 4. Glass samples exposed to outdoor at IES-UPM.

exposure to soiling. Each month one sample was removed from outdoors and the light transmission was evaluated. Results from the accumulated losses when the glass samples are not cleaned during a long period of time show how after one month, the losses in transmittance due to soiling are of $9 \%$. After 2 months, the losses increase to $11 \%$, and after three months of exposure, to $64 \%$.

\subsection{Effect of soiling in CPV systems: IES and ANU}

Most of the experiments have been carried out at the IES facilities (Fig. 5), using five different concentrator technologies and one flat panel. However, some testing was also performed at the ANU on the CHAPS CPV system.

\subsubsection{IES: diverse systems with several concentration ratios}

At the IES-UPM, a simple experiment has been carried out in order to evaluate the effect of soiling in PV



Fig. 5. Systems installed at IES-UPM test site. concentrators. Five systems with concentration levels between $2 \mathrm{X}$ and $300 \mathrm{X}$ and one flat module were subjected to testing.

Although the power output of a cell is the parameter of most commercial interest, its relationship with the captured light is affected by several factors including the cell technology of each module, the temperature and the electrical mismatch between the cells. However short circuit current $\left(I_{\mathrm{SC}}\right)$ is proportional to the total incident power and is only slightly affected by the temperature of the silicon cells used in the concentrators in this work. Thus $I_{\mathrm{SC}}$ provides the gauge of cell performance which is most sensitive to soiling. Various solar collectors were installed outdoors to become soiled over various time periods. The short circuit current of the systems, $I_{\mathrm{SC}}$, was checked immediately before and after periodically cleaning each collector with water.

The five concentration systems used were the Archimedes $2 \mathrm{X}$ and Archimedes 10X (Fig. 6) from ZSW (Germany),



Fig. 6. Archimedes 2-10X CPV systems and BP Solar flat module installed in the same tracking system. 
the Euclides $20 \mathrm{X}$ and Euclides $40 \mathrm{X}$ from the IES-UPM and a point focus Fresnel lens-based system operating at 300X (Sala et al., 2005). All the concentrators are installed at the IES-UPM test facilities (Madrid - Spain). The type of optics and geometric concentration ratio of each system are summarized in Table 2.

Both the Archimedes concentrators are single axis tracking systems, which rotate about their North-South orientated axis and are tilted at $30^{\circ}$ with respect to the horizontal plane. One BP Solar flat module is been installed on the same tracking frame as these concentration systems, so the dirt accumulation is similar for all three systems.

The different technologies used are described below:

1. Archimedes $2 \mathrm{X}$ (Fig. 7). CPV system with 'V' mirrors that concentrate the sunlight to about two suns onto the solar cells. Solar cells are passive cooled with aluminium fins in the back of the modules.

2. Archimedes 10X (Fig. 8). Cylindrical-parabolic through with a nominal geometric concentration level of $10 \mathrm{X}$. Solar cells are located in the mirrors back side, where there is also placed the passive finned cooling system.

3. BP Solar flat module.

4. and 5. Euclides 20X and Euclides 40X (Fig. 9). A horizontal single axis cylindrical-parabolic trough, orientated North-South, with active tracking. It uses passive

Table 2

Optical characteristics of each system.

\begin{tabular}{|c|c|c|c|}
\hline System & Collector & Type & $\begin{array}{l}\text { Geometric } \\
\text { concentration } \\
\text { ratio }(\mathrm{X})\end{array}$ \\
\hline Archimedes $2 \mathrm{X}$ & Glass mirror & Linear & 2 \\
\hline Archimedes $10 \mathrm{X}$ & Al film reflector & Linear & 10 \\
\hline Euclides $20 \mathrm{X}$ & $\begin{array}{l}\text { Curved glass, 2nd } \\
\text { surface }\end{array}$ & Linear & 20 \\
\hline Euclides $40 \mathrm{X}$ & $\begin{array}{l}\text { Curved glass, 2nd } \\
\text { surface }\end{array}$ & Linear & 40 \\
\hline Fresnel $300 \mathrm{X}$ & $\begin{array}{l}\text { PMMA Fresnel } \\
\text { lens }+ \text { reflexive pyramid } \\
\left(2^{\circ}\right)\end{array}$ & $\begin{array}{l}\text { Point } \\
\text { focus }\end{array}$ & 300 \\
\hline
\end{tabular}

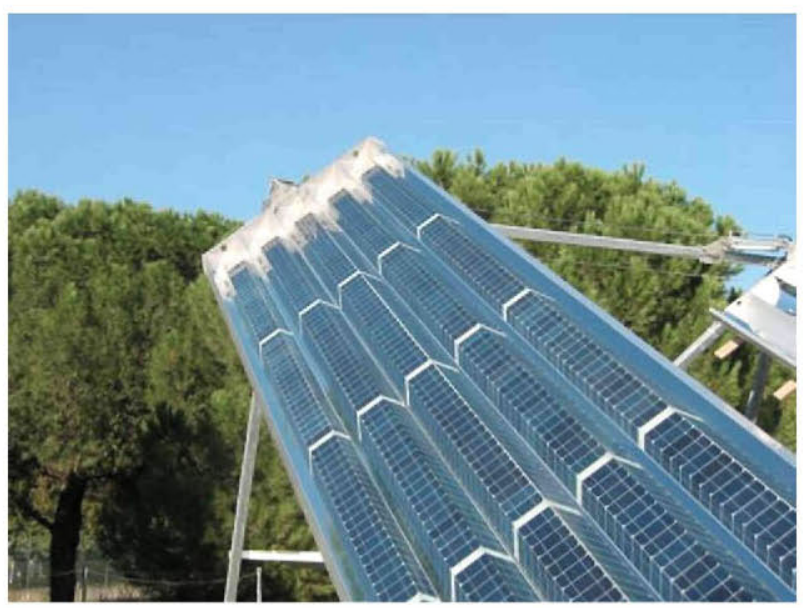

Fig. 7. Archimedes $2 X$ CPV system installed at IES-UPM. cooling with thin fins. Two levels of nominal geometric concentration are installed, 20X and $40 \mathrm{X}$, but effectively $14 \mathrm{X}$ and $28 \mathrm{X}$.

6. Fresnel lenses $300 \mathrm{X}$ concentrator module (Fig. 10). A point focus system with two axis tracking.

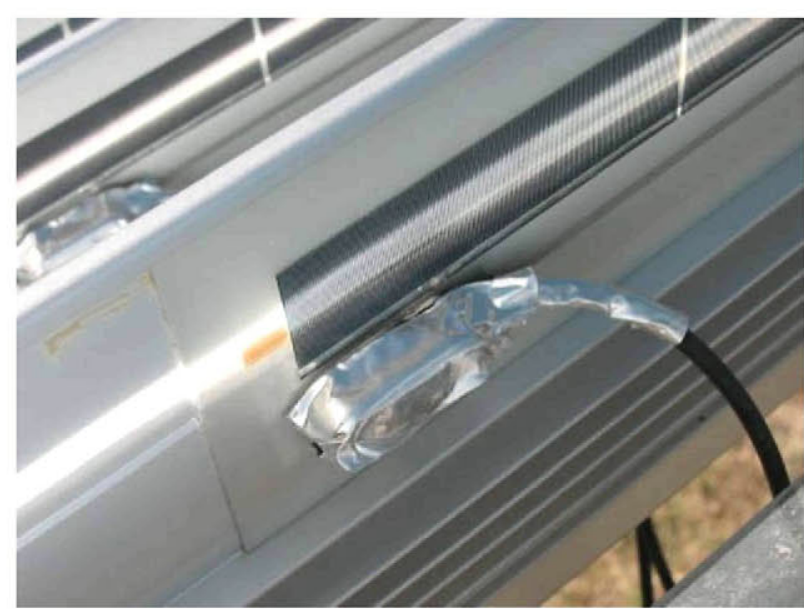

Fig. 8. Archimedes 10X CPV system installed at IES-UPM.



Fig. 9. Euclides 20X and Euclides $40 \mathrm{X}$ at IES-UPM.

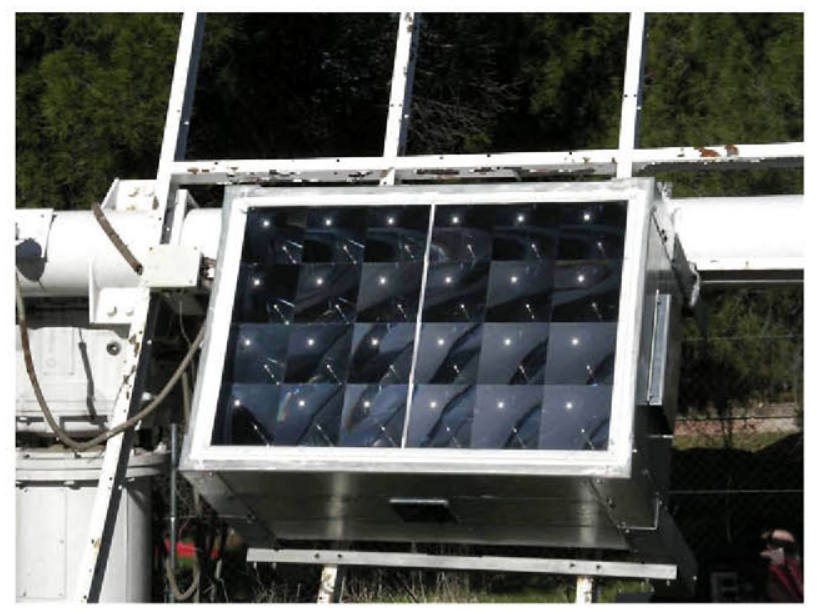

Fig. 10. Fresnel lenses point focus module (300X). 
Table 3

Results (November 2007, March 2008 and July 2008).

\begin{tabular}{lcclc}
\hline System & $\begin{array}{l}I_{\text {SC }} \text { before } \\
\text { cleaning } \\
\text { (A) }\end{array}$ & $\begin{array}{l}I_{\text {SC }} \text { after } \\
\text { cleaning } \\
\text { (A) }\end{array}$ & $\begin{array}{l}\text { Difference } \\
\text { in } I_{\text {SC }} \\
(\mathrm{A})\end{array}$ & $\begin{array}{l}\text { Losses due } \\
\text { to soiling } \\
(\%)\end{array}$ \\
\hline November 2007 & & & & \\
Archimedes 2X & 22.2 & 23.7 & -1.5 & 6.5 \\
Archimedes 10X & 15.1 & 18.1 & -3 & 16.8 \\
Flat panel - BP & 2.5 & 2.6 & -0.1 & 3.8 \\
March 2008 & & & & \\
Flat panel - BP & 2.9 & 2.9 & 0 & 1.2 \\
Archimedes 2X & 21.5 & 23.3 & -1.8 & 8 \\
Archimedes 10X & 10.7 & 12.7 & -2 & 15.5 \\
Euclides 40X & 22.1 & 30 & -7.9 & 26.2 \\
Euclides 20X & 9.7 & 12.6 & -2.9 & 23.2 \\
Fresnel module 300X & 3.9 & 4.5 & -0.6 & 12.3 \\
July 2008 & & & & \\
Flat panel - BP & 2.7 & 2.7 & 0 & 0 \\
Archimedes 2X & 23.8 & 24.7 & -0.9 & 3.9 \\
Euclides 40X & 24.9 & 31.6 & -6.7 & 21.2 \\
Fresnel module 300X & 6.9 & 7.3 & -0.4 & 5.6 \\
\hline
\end{tabular}

In November 2007 , three systems were initially subjected to experiment, the Archimedes 2X, the Archimedes 10X and the flat panel. After 5 months of exposure, $I_{\mathrm{SC}}$ was measured, and then each system was cleaned and measured again. Results are presented in Table 3.

The Archimedes CPV systems showed a greater increase in $I_{\mathrm{SC}}$ after cleaning in comparison with the flat module. For the Archimedes $2 \mathrm{X}$ it is about a 7\%; and for the Archimedes 10X, 17\%.This work infers that soiling has a more severe affect on reflective PV collectors with higher levels of concentration. Indeed it seems to be proportional to concentration ratio.

After a further 4 months (March 2008), a second test was performed. In this case, all the installed systems in the IES field were measured. Results are shown in Table 3.
In the second testing, the Archimedes CPV systems again showed a major increase of the $I_{\mathrm{SC}}$ after cleaning in comparison with the flat module. For the Archimedes $2 \mathrm{X}$ it was about $8 \%$; and for the Archimedes 10X, 16\%, which is similar to the first measurements. For the other systems, $I_{\mathrm{SC}}$ increased $23 \%$ for Euclides $20 \mathrm{X}$, for Euclides $40 \mathrm{X}$ had a $26 \%$ increase, and the Point Focus CPV 300X resulted in a $12 \%$ gain in $I_{\mathrm{SC}}$. Only a slight difference can be observed from the trend established in the first test for the group of reflective-optics concentrators.

The data from the two tests, November 2007 and March 2008, show consistent results.. After these first two measurements, it seems that the performance when the concentrators are soiled is similar in both cases. The effect of soiling seems to depend on the nature and geometry of the optics. Linear reflective optics $(2 \mathrm{X}, 10 \mathrm{X}, 20 \mathrm{X}, 40 \mathrm{X})$ are more severely affected by soiling than the $300 \mathrm{X}$ point focus refractive concentrator.

After a further 4 months (July 2008) a third group of measurements were performed. In this case, concentrators tested were the Archimedes 2X, Euclides 40X and the Fresnel module of $300 \mathrm{X}$. Increases in $I_{\mathrm{SC}}$ due to cleaning were established as $4 \%$ for $2 \mathrm{X}$ reflective, $21 \%$ for $40 \mathrm{X}$ reflective and $6 \%$ for $300 \mathrm{X}$ lens.

When the results from the three tests are plotted as a function of the concentration ratio (Fig. 11), it is observed that the degradation of the current of linear reflective concentrators is approximately linear with concentration ratio. However, the point focus refractive concentrators are substantially less susceptible to soiling. But considering that the acceptance angle of the point focus geometry is related to the square root of the concentration level, these values are closer to the linear ones.

When all the linear reflective concentrator results are plotted on the same graph, two groups of reflective concentrators can be distinguish separately. Those ones using a front surface reflector such as the Archimedes units which



Fig. 11. $I_{\mathrm{SC}}$ losses vs. concentration level (all concentrators). 
incorporate a very thin reflector made of an aluminium foil and those concentrators with a second-surface reflector such as the EUCLIDES, which has a mirror made of $3 \mathrm{~mm}$ thick glass in front of the silver layer. Second-surface optics suffers higher reductions in efficiency due to soiling.

\subsubsection{ANU: CHAPS System}

The Combined Heat and Power System (CHAPS) (Fig. 12) is a PV/Thermal installation incorporating eight roof mounted single axis reflective solar concentrating collectors. The mirrors are made of glass $1 \mathrm{~mm}$ thick with a rear silver layer reflector and provide concentration ratio is $38 \mathrm{X}$. Each collector is $24 \mathrm{~m}$ long and comprises a tracking support structure that is controlled by a microprocessor. Heat is removed using a fluid, which flows through the receiver. The fluid then passes through a heat exchanger that transfers heat to hot water storage tanks. The orientation of the building is rotated $37^{\circ}$ away from True North.

A test was conducted on the short circuit current (Fig. 13) before and after cleaning of the CHAPS Collector number 1 to determine the typical degradation due to soiling. This

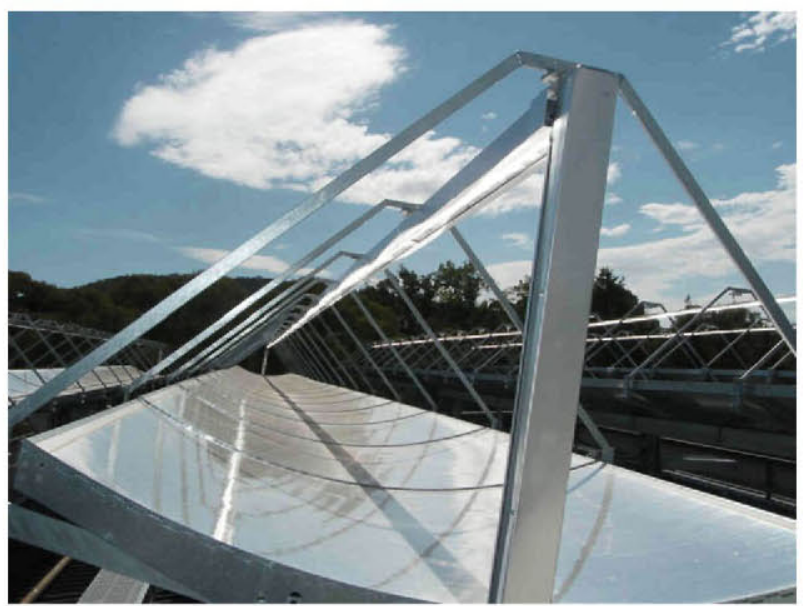

Fig. 12. Combined Heat and Power System (CHAPS) at Australian National University.

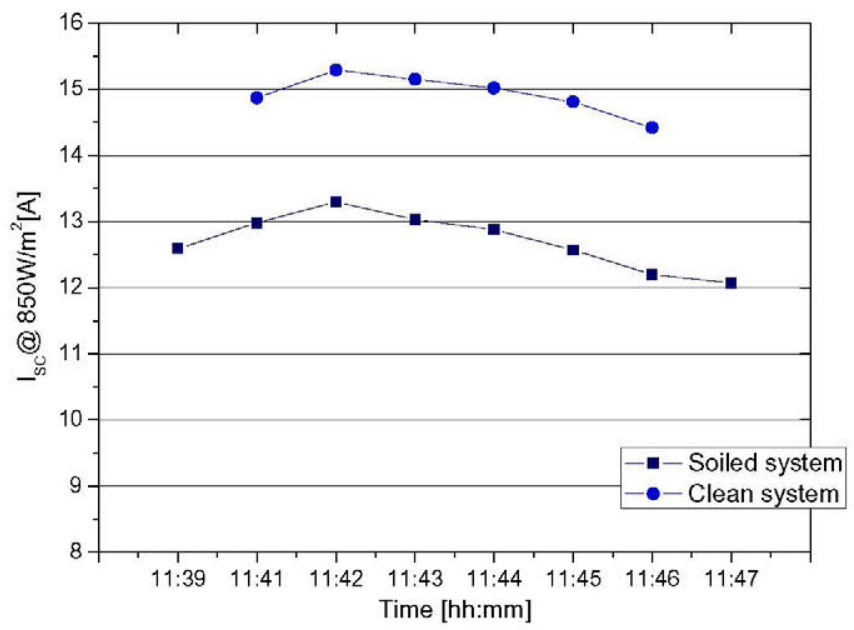

Fig. 13. CHAPS system: $I_{\mathrm{SC}}$ at collector 1 before and after cleaning.
Table 4

CHAPS system: comparison of $I_{\mathrm{SC}}$ values before and after cleaning collector 1 in consecutive days.

\begin{tabular}{lllll}
\hline Day & $\begin{array}{l}I_{\text {SC }} \text { before } \\
\text { cleaning }(\mathrm{A})\end{array}$ & $\begin{array}{l}I_{\text {SC }} \text { after } \\
\text { cleaning }(\mathrm{A})\end{array}$ & $\begin{array}{l}\text { Difference in } \\
I_{\text {SC }}(\mathrm{A})\end{array}$ & $\begin{array}{l}\text { Losses due to } \\
\text { soiling }(\%)\end{array}$ \\
\hline 1 & 13 & 14.9 & -1.9 & 12.7 \\
2 & 13.3 & 15.3 & -2 & 13 \\
3 & 13 & 15.1 & -2.1 & 14 \\
4 & 12.9 & 15 & -2.1 & 14.3 \\
5 & 12.6 & 14.8 & -2.2 & 15.2 \\
6 & 12.2 & 14.4 & -2.2 & 15.4 \\
\hline
\end{tabular}

unit had not had active cleaning beforehand for 3 months. The electrical output was degraded by soiling by up to $15 \%$ (Table 4). This initial test obtained a mean value for loss due to soiling of $14 \%$. It would be of great interest to conduct ongoing testing in order to compare these figures with results for Euclides 40X.

\section{Conclusions}

CPV systems are more sensitive to soiling than flat panels, accumulating losses in $I_{\mathrm{SC}}$ of about $14 \%$ on average in three different tests conducted at IES-UPM test site in Madrid. Moreover, some concentrators reached losses up to $26 \%$ when the system was soiled for 4 months of exposure. In general, linear reflective optics suffers greater losses due to soiling than refractive optics. In a refractive optical device, the light has a single passage through the soiled layer. However, in a reflective surface, the light has the possibility of two interactions with particles of dirt and so the losses can be larger. At the same time, there is a relationship between the $I_{\mathrm{SC}}$ losses and the concentration level in the case of systems using reflective optics.

It is important to take into account the effect of soiling in CPV systems because the reduction of the energy output in certain cases is significant. However, losses due to soiling are site specific and difficult to generalise. It should be studied in relation to each system bearing in mind that specific characteristics of the location may dictate an appropriate pattern for cleaning.

On the other hand, there is substantial effort in laboratories to improve the performance of cells by a few percentage points in efficiency, sometimes requiring expensive processes. This effort is wasted if the same level of care is not taken in the field installation to minimise the effect of soiling. Cleaning implemented at an economically optimised frequency is a simple method of improving electricity production by both CPV and non-concentrating systems.

\section{Acknowledgements}

This work has been supported by the Comunidad de Madrid within the NUMANCIA Programme (S-05050/ENE/ 0310). It has also been supported by the Spanish Ministry of Education and Science under Consolider Ingenio 2010 Program, trough the Project GENESIS-FV (CSD200060004). 


\section{References}

Becker, H., Vaaben, W., Herrmann, W. 1996. Reduced output of solar generators due to pollution. In: 14th European Photovoltaic Solar Energy Conference and Exhibition. Barcelona, Spain.

Haeberlin, H., Graf, J.D., 1998. Gradual reduction of PV generator yield due to pollution'. In: 2nd World Conference on Photovoltaic Solar Energy Conversion, Vienna, Austria.

Hottel, H.C., Woertz, B.B., 1942. The performance of flat-plate solar-heat collectors. ASME Transactions 64, 91-104.

Biryukov, S., Faiman, D., Goldfeld, A., 1999. An optical system for the quantitative study of particulate contamination on solar collector surfaces. Solar Energy 66, 371-378.

Garg, H.P., 1974. Effect of dirt on transparent covers in flat-plate solar energy collectors. Solar Energy 15, 299-302.

Deffenbaugh, D.M., Green, S.T., Svedeman, S.J., 1986. The effect of dust accumulation on line-focus parabolic through solar collector performance. Solar Energy 36, 139-146.

Hammond, R., Srinivasan, D., Harris, A., Whitlfield, K. Effects of Soiling on Radiometer Performance. In: 26th PVSEC, 1997, Anaheim, USA.
Hegazy, A.A., 2001. Effect of dust accumulation on solar transmittance through glass covers of plate-type collectors. Renewable Energy 22, 525-540.

Elminir, H.K., Ghitas, A.E., Hamid, R.H., El-Hussainy, F., Beheary, M.M., Abdel-Moneim, K.M., 2006. Effect of dust on the transparent cover of solar collectors. Energy Conversion and Management 47, 31923203.

Stone, K.W., Garboushian, V., Dutra, D., Hayden, H., 2004. Four years of operation of the AMONIX high concentration photovoltaic system at arizona public service utility. In: Solar 2004 - A Solar Harvest: Growing Opportunities, Oregon, USA.

Herrero, R., 2008.Effect of soiling in single optical devices: measurement of the light dispersion using a CCD camera. IES Internal Report.

Sala, G., Pachón, D., Vivar, M., Antón, I., Möhring, H.-D., Klotz, F.H., Morilla, C., Fernández, J.M., Martinelli, G., Stefancich, M., Malagú, C., Eames, P., Mallick, T., Luque-Heredia, I., Cervantes, R., 2005. IDEOCONTE project: searching the best Si-cells PV concentrator. In: 20th European Photovoltaic Solar Energy Conference and Exhibition, Barcelona, Spain. 